\title{
O CORPO ENTRE A AUSÊNCIA E O EXCESSO EM NARRATIVAS DECADENTISTAS
}

\author{
BRAGA, Débora Renata de Freitas ${ }^{1}$ \\ SILVA, Allison Marcos Leão da ${ }^{2}$
}

RESUMO: Partindo da leitura de algumas narrativas decadentistas, como a novela A Confissão de Lúcio, de Mário de Sá-Carneiro e os contos "O Mistério da Árvore”, de Raul Brandão, "Suze”, de António Patrício e "A Ruiva", de Fialho de Almeida, este artigo tem como objetivo fazer uma análise das representações do corpo de personagens a partir de duas vertentes: a ausência e o excesso, especialmente no que se refere à configuração dos olhos e dos cabelos. Pretende-se demonstrar como as figuras oscilam entre a representação do cadáver, da morte e da decomposição, e, por outro lado, dos traços da prototípica Salomé, musa da estética decadentista.

PALAVRAS-CHAVE: Literatura Portuguesa, Decadentismo, Corpo, Morte, Salomé.

\section{THE BODY BETWEEN ABSENCE AND EXCESS IN DECADENTISTS NARRATIVES}

\begin{abstract}
Beginning with the reading of some decadent narratives, such as the novel A Confissão de Lúcio, by Mário de Sá-Carneiro and the tales "O Mistério da Árvore”, by Raul Brandão, "Suze", by António Patrício and "A Ruiva", by Fialho de Almeida, this article aims to make an analysis of representations of the body of characters from two strands: absence and excess, especially with regard to the configuration of the eyes and hair. It is intended to demonstrate how the figures oscillate between the representation of the corpse, death and decomposition, and, on the other hand, of the traits of the prototypical Salomé, muse of the decadent esthetics.
\end{abstract}

KEYWORDS: Portuguese Literatura, Decadentism, Body, Death, Salomé.

\footnotetext{
${ }^{1}$ Mestre em Letras pela Universidade do Estado do Amazonas (UEA). Professora do Colégio Militar de Manaus. E-mail: deborarenatabraga@yahoo.com.br

${ }^{2}$ Doutor em Letras pela Universidade Federal de Minas Gerais (UFMG). Professor da Universidade do Estado do Amazonas e do Mestrado em Letras e Artes da mesma instituição. E-mail: allisonleao@yahoo.com.br.
} 
A tela A lição de anatomia do Dr. Tulp (1632), de Rembrandt, evoca o propósito da literatura naturalista de esmiuçar o comportamento humano como um construto social. O Realismo e o Naturalismo legaram-nos um arcabouço riquíssimo e detalhado de espaços coletivos (como é o caso, no Brasil, d'O Cortiço e da Casa de Pensão, de Aluísio Azevedo), e adentrou também o espaço íntimo de alcovas burguesas, refúgios amorosos e quartos de empregada, nas narrativas do português Eça de Queirós. Mas se o espaço é dissecado, ao gosto da lição de anatomia representada na tela de Rembrandt, que se pode dizer dos corpos que por ele transitam?

O poeta Antero de Quental, um dos líderes da estética realista em Portugal, apresentou em 1871, nas Conferências do Casino, as Causas da decadência dos povos peninsulares nos últimos três séculos, ${ }^{3}$ a fim de explicar o atraso do povo português em relação ao restante da Europa. A consciência histórica de que ao apogeu segue o declínio marca a passagem do século XIX para o XX em Portugal. A segunda metade do século XIX “é um desses momentos em que determinada cosmovisão começa a entrar em crise, em que começa a ruir o edifício da civilização burguesa" (BARCELLOS, 1985, p. 45). A estética decadentista encontrou seu lugar na atmosfera pessimista de fim de século, especialmente por conta da humilhação pela qual os portugueses passaram no episódio do Ultimato Inglês, de 1890, no qual o país perdeu a soberania que pretendia obter sobre os territórios entre Angola e Moçambique, o famoso Mapa Cor-de-Rosa. Os portugueses, "desgostados de si mesmos e de uma civilização em crise aberta" (PEREIRA, 1975, p. 23), viram o sentimento de declínio que perpassou a História e a Economia penetrar na Arte. A literatura decadentista é uma reação contra o positivismo e o cientificismo que marcaram a estética realista e naturalista. É o espaço do simulacro, do excesso, da sinestesia,

sob o primado destas tendências temático-formais (a que poderíamos acrescentar, entre outras, o amor ritualmente lascivo e inibitório, o fascínio pela figura ambivalente de Salomé, tal como surgia nos quadros do pintor simbolista Gustave Moreau, o erotismo anómalo, a volúpia transgressiva do vício e do sangue, o imaginário nosológico, monstruoso e necrófilo) (IDEIAS, $2009, \mathrm{~s} / \mathrm{p}$.).

\footnotetext{
${ }^{3}$ Como já o fizera Montesquieu, em Considérations sur les causes de la grandeur des romains et de leur décadence (1734), e posteriormente, Abel Lefranc, em Essai sur les causes et les effets de la perfection et de la décadence des lettres et des arts (1899) (cf. IDEIAS, 2009).
} 
O homem finissecular vive "de si para si, mergulhado em reminiscências, elaborando sonhos, transfigurando pesadelos, arquitetando um mundo à sua imagem e semelhança" (MUCCI, 1994, p. 48). Não raras são as representações de personagens ou narradores isolados, que se desvincularam deliberadamente da vida ou do convívio social, atitude representada pela expressão "torre de marfim", ${ }_{4}^{4}$ que distingue o decadentismo da arte engajada ou utilitária. Como afirma Latuf Isaías Mucci, "o decadentista correu para dentro de si mesmo e construiu uma nova e elevada torre de marfim, quase sem janelas para o exterior - que ele abominava -, mas com inúmeras brechas para o seu interior" (1994, p. 48).

$\mathrm{Na}$ perspectiva do decadentismo, refletindo o sentimento de crise que assolava o período, "da ideia de que a arte cria uma segunda natureza, passa-se à ideia de que é arte qualquer violação - o mais bizarra e mórbida possível - da natureza" (ECO, 2010, p. 340). As narrativas decadentistas apresentam um séquito de personagens deformados - de corpo e de atitudes, pois o "Decadentismo rompe com a representação simbólica, inaugurando a estética da alegoria: o belo em ruínas, ou a ruína do belo, prefaciando o cenário de cinzas da modernidade e da pós-modernidade" (MUCCI, 1994, p. 61). Seja pela condição socioeconômica, pelo meio vicioso em que vivem, ou mesmo pela ausência de valores, o corpo dos personagens toma a forma da degenerescência e da putrefação ainda em vida.

Segundo Leandro Cardim, o corpo é, "ao mesmo tempo, o que limita e abre a experiência" (2009, p. 89). A fim de desconcertar os valores da razão positivista, na estética decadentista, o corpo traz a marca da doença, dos desejos indomados, e é a representação do mal-estar finissecular: uma estética do feio e do grotesco. Remo Bodei (2005), ao categorizar o conceito de feio de acordo com as épocas, afirma que, em determinado momento, o feio já não se distingue do belo, e a arte torna-se o espaço das deformidades do corpo e da alma. Nesta perspectiva, o feio "nada mais é do que a beleza rebelde e perversa, Lúcifer, decaído por causa de sua desmedida soberba" (2005, p. 150).

Uma das figurações da feiura é o grotesco, o qual é "quase sempre o resultado de um conflito entre cultura e corporalidade" (SODRÉ; PAIVA, 2002, p. 60). Segundo Wolfgang Kayser, "las representaciones de lo grotesco constituyen la oposición más ruidosa y evidente a

\footnotetext{
${ }^{4} \mathrm{O}$ termo "tour d'ivoire" foi utilizado por Augustin Sainte-Beuve no poema "Pensées d'Aôut, à M. Villemain", de 1837, a fim de distinguir a poesia abstrata de Alfred de Vigny da arte utilitarista de Victor Hugo (cf. ALMEIDA, 2009).
}

Jangada | nr. 14, jul/dez, 2019 | ISSN 2317-4722 
toda clase de racionalismo y cualquier sistemática del pensar" (1964, p. 229). ${ }^{5}$ Pensar o corpo grotesco, o corpo feio, a (de)formação dos personagens como parte do discurso decadentista de opor-se à naturalidade das coisas significa vê-lo não apenas como "um mero elemento material, uma superfície cuja permeabilidade é politicamente regulada” (BUTLER, 2003, p. 34). De acordo com Nilton Milanez,

ao observarmos tais mecanismos que constroem o corpo como discurso, destacando sua existência material, teremos, antes de mais nada, a pergunta: que tipo de conhecimento vai produzir o corpo no discurso? Quais práticas discursivas entrelaçam essa materialidade corpóreo-discursiva? Que artes do existir essa prática corporal discursiva coloca em evidência? (2010, p. 216).

O corpo, como espelho da interioridade do ser, produz impressões. Conforme Jean-Yves Leloup, a pele é um "ponto sensível do contato com o mundo e podia ser também um abismo, [...] o código mais intenso, um lar de profundas memórias” (2012, p. 9). Tão fragmentário quanto a memória é o corpo, inscrito em uma história e marcado por ela. Foucault afirma que o corpo é a "superfície de inscrição dos acontecimentos (enquanto que a linguagem os marca e as ideias os dissolvem), lugar de dissolução do Eu (que supõe a quimera de uma unidade substancial), volume em perpétua pulverização" (1979, p. 22).

Mas de que corpo se fala? O corpo como construto textual, parte do projeto estético de recusa ao real, ao natural. Em várias narrativas decadentistas, o corpo "narra o que mostra como nas imagens visuais e no discurso do sonho" (FERNANDES, 2003, p. 34): o corpo significa, ele é signo e linguagem. Ao investigar a materialidade do corpo, percebe-se que ele "revela trechos da história a que pertence" (SOARES, 2006, p. 110). O corpo torna-se, portanto, (en)carnação da crise finissecular. Segundo Etcoff, "a aparência é o nosso sacramento, nosso ser ou não ser atraente, o ego invisível que o mundo presume ser o espelho do ego invisível, interior. Ninguém pode resistir à aparência" (1999, p. 15). Nas narrativas decadentistas, o corpo dos personagens funde-se ao espaço, ambos vistos sob a lente do grotesco, como reconhece Raul Brandão (1984) na novela A Farsa, ao afirmar que obteve inspiração

\footnotetext{
${ }^{5}$ Tradução: "as representações do grotesco constituem a oposição mais ruidosa e evidente a toda classe de racionalismo e qualquer sistemática do pensar".
} 
nos quadros de Rembrandt, deformando os tipos, exagerando-lhes as papeiras e os gadanhos, avolumando-lhes as barrigas inchadas, os seios engelhados e todas as deformidades com ferocidade e grotesco, $[\ldots]-$ até ao ponto de vermos remexer lá no fundo do poço animais gelatinosos - que vivem na água esverdeada sonhando na pesa e remoendo sempre o sumidouro das bocas horríveis e frias como as dos cadáveres. A sombra é um grande pintor $(A F, \mathrm{p}$. 23-24).

Vítor Viçoso afirma que as obras de Raul Brandão possuem um "acentuado pendor ético-social" (2003, p. 39), o que não pode ser ignorado em seu processo de criação. Ao contrário do isolamento na torre de marfim, na qual as mazelas do mundo são ignoradas, na obra brandoniana, temos a representação dos oprimidos, pobres e marginais, que "saem do imaginário de um autor solidário com os que sofrem [...], através de uma análise espectral da degenerescência física e espiritual, que se configura em imagens obsessivas de descarnação, de petrificação, de mecanização e de morte" (REYNAUD, 1999, p. 121-122). A ideia de ruína penetra na própria anatomia do personagem, uma "identidade frágil, instável, descentrada, mutante, processual e inconstante à qual corresponde um corpo fragmentado" (TUCHERMAN, 2004, p. 94). Na narrativa brandoniana, as relações de poder e o fator opressão social acabam por projetar-se nos corpos, como signos. Como afirma Jean-Jacques Courtine, “o corpo é também diretamente mergulhado num campo político; as relações de poder operam sobre ele uma influência imediata; elas investem contra ele, o marcam, o adestram, o supliciam" (2013, p. 16).

No conto "O mistério da árvore", 6 de Raul Brandão (1981), a diferença entre opressor e oprimido marca-se no corpo dos personagens. Os dois mendigos apaixonados contrastam com o Rei, cuja presença assemelha-se à arvore enorme, seca e esgalhada em frente ao palácio, e que servia de forca. Na descrição dos amantes, o narrador ressalta que "nem sequer eram extraordinariamente belos, mas deles irradiava uma força imensa - daquela moça sardenta, com resquícios de palha pegados aos cabelos, daquele homem cuja carne aparecia entre os farrapos" (OMA, p. 100). Já o Rei tirano não possui uma presença corpórea delineável, embora seja associado constantemente à secura e esterilidade da árvore: "não podia amar. Nem a voluptuosidade, nem o ideal, nem o amor, nem a carne láctea das mulheres: tudo lhe era vedado"

\footnotetext{
${ }^{6}$ A referência ao conto "O mistério da árvore" será feita por meio da sigla $O M A$.
} 
(OMA, p. 102). De acordo com Pierre Bourdieu, acerca da constituição do físico como marca distintiva,

o corpo é a mais irrecusável objetivação do gosto de classe, que manifesta de diversas maneiras. Em primeiro lugar, no que tem de mais natural em aparência, isto é, nas dimensões (volume, estatura, peso) e nas formas (redondas ou quadrados, rígidas e flexíveis, retas ou curvas, etc...) de sua conformação visível, mas que expressa de mil maneiras toda uma relação com o corpo, isto é, toda uma maneira de tratar o corpo, de cuidá-lo, de nutri-lo, de mantê-lo, que é reveladora das disposições mais profundas do habitus (2007, p. 188).

Assim, as "figuras perversas, prostitutas, esfinges, donzelas moribundas, rostos marcados pelo desagradável" (ECO, 2007, p. 352) da literatura decadentista revelam dois interesses, sendo que o primeiro deles é um notório interesse pela putrefação e pelo mórbido. Na poesia, desfilam as tísicas de António Nobre e Cesário Verde, e a tristíssima moça de Gomes Leal, ${ }^{7}$ na prosa, Fialho de Almeida (1914) apresenta, no conto "A Ruiva", 8 a menina Carolina, filha do coveiro Farrusco, que prefere dormir em túmulos vazios a conviver com a moça. Carolina é representada como uma menina "enfezadita dos nervos" ( $A R$, p. 149$)$ por conta de frustrações sexuais: "era a febre do sangue inficionado pelos microzimas do vício e o desejo de cadela nubente que uma força espicaça de irritantes curiosidades e terrores deliciosos" ( $A R, \mathrm{p}$. 155). Na representação de Carolina, percebe-se a ideia de "feiura evocada pelo sexo, isso que aí nos fere, é a ameaça de perder a face humana, de se animalizar, de se tornar monstruoso" (FEITOSA, 2004, p. 33). Carolina acostumou-se, desde pequena, à presença dos defuntos no Cemitério dos Prazeres, seu sombrio lar. Comprazia-se em tocar o corpo dos cadáveres de moços jovens, até conhecer, por intermédio da alcoviteira Marcelina, João, o loiro que desejava, com quem logo se amasia. A relação desmorona devido à falta de higiene de Carolina com a casa e com o próprio corpo. Por fim, Marcelina aconselha Carolina a encontrar trabalho em uma fábrica, onde a moça se perde em vícios, e acaba por prostituir-se, vindo a morrer de tuberculose.

\footnotetext{
${ }^{7}$ Referência ao poema "Pobre tysica!", de António Nobre; "Contrariedades", de Cesário Verde e "Tristíssima", de Gomes Leal.

${ }^{8}$ A referência ao conto "A Ruiva"será feita por meio da sigla $A R$.
} 
No início do conto, descobre-se que Carolina "deitava sangue pela boca” ( $A R$, p. 148). Não só a doença a corroía, como também o desejo pelos homens sem vida que o pai tinha por função enterrar: "na sua sinceridade confessava-se horrível, cheia de afinidades com a hiena. Nunca mais iria exaltar-se perante homens sem vida. Que infâmia! Agora tinha o seu João, carnes brancas, de semideus" ( $A R$, p. 162). Ao conhecer João, seus desejos outrora interditados podem finalmente libertar-se, o que ocasiona transformações no corpo de Carolina: "os seios ampliaram-se numa curva graciosa, de contorno quase casto; e esmaltado de palidez mórbida, lasciva e um pouco cismadora, o seu rosto era doce, de uma harmonia dolente, como certas pinturas de virgens mártires" ( $A R$, p. 194).

Ao iniciar a vida de prostituição, a personagem ganha contornos grotescos: "as gengivas tinham-se-lhe descarnado, pintava os beiços com carmim” ( $A R$, p. 204). Os lábios vermelhos e a roupa justa só contribuem para acentuar a deformação (física e moral) da personagem: "apertava a cintura e os flancos com espartilhos que a estrangulavam em duas metades, deixando-lhe o tórax afunilado e hirto, o fígado opresso e a respiração entrecortada" ( $A R, \mathrm{p}$. 204). Restou-lhe a "cara chupada e amarela, onde entre círculos roxos luziam dois olhos febris" $(A R$, p. 205). Foi o pai quem a sepultou sem emoção alguma, pois se tratava apenas de um corpo a quem lhe cabia enterrar: "Foi o tio Farrusco quem cobriu de terra, sem comoção nem saudade, o corpo espedaçado pelo seu escalpelo, da rapariga corroída de podridões sinistras" (AR, p. 205). A narrativa encerra com a descrição da caveira da personagem, analisada friamente pelo narrador: "Tenho sobre a minha banca neste momento a sua caveira fria, limpa de películas e cartilagens, branca e escarninha, cujas maxilas escancaram diante de mim, numa careta trágica, a sua concavidade cheia de sombra" (AR, p. 205).

A descrição dos demais personagens de "A Ruiva" também não escapa aos tons de grotesco. Em um cenário permeado por "coveiros angulosos e vesgos lançando-se de si um fétido deletério" ( $A R$, p. 146), destaca-se Laureana, a balconista da Taberna do Pescada, de "grandes seios e arrecadas" ( $A R$, p. 146), cujo "hálito empestava a dez passos" ( $A R$, p. 147). Não menos repelente é a figura da alcoviteira Marcelina, "uma pessoa baixa e vagarosa, aspecto redondo e roxo de hemorroida, feridas na perna emplastada" ( $A R$, p. 157). Em Marcelina, "a massa dos seios papuda e molemente batida por mais de meio século, arrotos estrondosos..." $(A R$, p. 158) trazem à tona uma representação decadente associada à imoralidade de seu comportamento. Da mesma boca de onde brotam as obscenidades e os maus conselhos, surge "um dente trôpego, único e esquecido, esverdinhava-lhe na boca desmobilidada; as barbicas 
hirsutas recordavam uma gata mansinha que se corcova, elétrica, sob as festas do dono" ( $A R$, p. 157). Já a mulata que vivia com a alcoviteira, de "fundas olheiras, olhos de carneiro mal morto" (AR, p. 158), é uma morta-em-vida, cujo "crânio pequenino de estúpida, de grande bestiaga, tinha a calva depressão idiota de uma cabaça oca” ( $A R$, p. 158). E eis que, na galeria dos mortos-em-vida, a representação que salta aos olhos é a do coveiro Farrusco, pai de Carolina, de

aspecto repelente, perfil áspero e cortante, descarnadas as faces, as mãos aduncas e gastas, cheias de terra e de cabelos. Sobre a testa, de uma polegada de largo, caíam grenhas fermentadas; as orelhas desapareciam-se-lhe sob a lã sebácea de um barrete cinzento; por um rasgão da camisa, furava uma moita de cabelos hirsutos, brancos como um pé de junco seco, nascido entre as pedras de um muro arruinado de azenha decrépita. Quase lhe ficavam pelas esquinas a que se encostava os farrapos em que embrulhava o corpo esquelético e lustroso, como de couro curtido ( $A R$, p. 148).

O segundo interesse dos decadentistas parece recair sobre o estigma da mulher fatal, a mulher Salomé, marca da sedução e da destruição, o "emblema que serpenteara a agonia finissecular" (COUTINHO, 2002, p. 66). Na novela A confissão de Lúcio, ${ }^{9}$ de Mário de SáCarneiro (1995), as personagens Americana e Marta têm o corpo marcado pelo excesso de luminosidade, de cor e de beleza, como se fossem um duplo, sugerindo a ideia de que o corpo "está a desaparecer, por motivos que se relacionam com a crise do sujeito moderno, perplexo diante das simulações e dos duplos que põem em questão a sua principal noção de realidade" (TUCHERMAN, 2004, p. 94). A Americana era "uma criatura alta, magra, de um rosto esguio de pele dourada - e uns cabelos fantásticos, de um ruivo incendiado, alucinante" ( $A C L$, p. 8), enquanto Marta era "uma linda mulher loira, muito loira, alta, escultural - e a carne mordorada, dura, fugitiva. [...] Um rosto formosíssimo, de uma beleza vigorosa, talhado em ouro. [...] Sempre triste - numa tristeza maceradamente vaga" ( $A C L$, p. 30). A ruiva americana é possuidora das belezas "que inspiram receio" $(A C L$, p. 8) no público que a vê dançar em meio ao ambiente artificial de seu palácio, e que termina em um suicídio artisticamente engendrado.

\footnotetext{
${ }^{9}$ A referência à novela $A$ confissão de Lúcio será feita por meio da sigla $A C L$.
} 
Salomé é considerada a musa do decadentismo, e é evocada na própria concepção física de Marta, cujo corpo é "bêbado de carne - aromático e lustral, evidente... salutar" (ACL, p. 42). As personagens criadas sob o estigma de Salomé evocam desejo e destruição, um efeito de prazer e terror sobre os homens nos quais pousa seu olhar. Os olhos, inclusive, são um dos aspectos do corpo feminino sobre os quais recai a obsessão dos decadentistas, assim como os cabelos, pois, de acordo com Louis Forestier, "symbolism seems to be particularly involved with eyes and hair" (1983, p. 107). ${ }^{10}$ Os cabelos, associados à feminilidade, com uma vaga associação à Medusa mitológica, são a característica física mais marcante de Carolina, a ruiva necrófila do conto de Fialho de Almeida, que "passava horas penteando os seus cabelos ruivos, anelados e finos de lustro macio e espessura abundante" ( $A R$, p. 194). No conto de Raul Brandão, a mendiga surge "envolta na palha dos cabelos louros" (OMA, p. 99). Na novela de Sá-Carneiro, o narrador destaca o "tipo característico da adolescente pervertida, magra - porém de seios bem visíveis -, cabelos de um louro sujo" ( $A C L$, p. 15) de uma das dançarinas, enquanto a Americana é descrita como um retrato repleto de luminosidade e cor: "os cabelos fulvos tinhaos enrolado desordenadamente e entretecido de pedrarias que constelavam aquelas labaredas em raios de luz ultrapassada. Mordiam-se-lhe nos braços serpentes de esmeraldas" (ACL, p. 1314).

No conto "Suze", 11 de António Patrício (1979), o narrador rememora sua relação com a prostituta homônima. Um dia, ela revela a necessidade de operar-se, e ele, em um processo de neurose, supõe que ela morre, e começa a colecionar detalhes da aparência e do jeito de ser da personagem, configurada com a "tinta de viciosa pálida" $(S$, p. 84), com "mãos da podridão" ( $S$, p. 142). Forestier aponta que "hair had long been associated with sensual responses" (1983, p. 107), ${ }^{12}$ e a característica mais marcante de Suze eram os "cabelos impossíveis, abusivos, excessivos, caíam-lhe nos ombros" ( $S$, p. 90). Tal é a fixação do narrador pelos cabelos de Suze, que ele chega a imaginá-la ainda mais bela com os cabelos desarrumados, depois de morta: "não te souberam pentear; deixaram-te o cabelo em desalinho e, não sei por quê, está mais claro, de uma seda mais pura, mais de infância" $(S$, p. 101). A pureza evocada no pós-morte substitui o artificialismo dos cabelos em vida:

\footnotetext{
${ }^{10}$ Tradução: "simbolismo parece estar particularmente envolvido com os olhos e o cabelo".

${ }^{11}$ A referência ao conto "Suze" será feita por meio da sigla $S$.

12 Tradução: "cabelo havia sido associado com respostas sensuais".
} 
os seus cabelos de criança escandinava, loiro cendrado e seda palha em que havia reflexos quase brancos, tufava na testa sob o chapéu preto, descaíam à esquerda, subiam à direita recortando a têmpora em ogiva, inverossímeis como raios de um sol de vício, químicos, absurdos... Só depois me convenci de que eram autênticos ( $S$, p. 85).

Forestier, acerca da força do olhar feminino, afirma que "their pupils attract those who stare at them" (1983, p. 107). ${ }^{13}$ Em Marta, o “olhar azul perdia-se de infinito” (ACL, p. 30). Já a ruiva Carolina, por exemplo, ao encher-se de desejo pelo amante, ficava com os "olhos úmidos, em cujas íris de inquietadas fibrilhas havia um contrair de comoções refreadas, luzia a cáustica lascívia do desejo incendido" (AR, p. 166). A sensualidade sem freios de Carolina atingia João de tal forma, que "com ela, a sua força, a sua forma vigorosa e superior, acobardava-se, quebrantava-se, caía: era então dos sentidos" ( $A R$, p. 190). Notam-se contornos demoníacos do poder que exerce o olhar de Carolina sobre João: "uma corrente galvânica percorria-o, nascida no olhar dela, sequioso e feroz, cheio de gula e de fel” (AR, p. 195). Já a Suze de António Patrício possuía o "olhar de chama" ( $S$, p. 141) e os "olhos claros, cinzento de água em névoa" ( $S$, p. 130), que bem poderiam ser comparados aos olhos de um cadáver. Mesmo sob a desconfiança de que Suze está morta, o narrador não se furta a desejar beijar os olhos mortos da amada.

Algumas personagens associam-se à androginia, e despertam certa tendência à violência, como as dançarinas de A confissão de Lúcio. A primeira possuía pernas que “despertavam desejos brutais de as morder, escalavradas de músculos, de durezas masculinamente" ( $A C L$, p. 15). A segunda dançarina "era uma rapariga frígida, muito branca e macerada, esguia, evocando misticismos, doença, nas suas pernas de morte - devastadas" (ACL, p. 15). A representação da mulher "tocada pela androginia" (MUCCI, 1994, p. 53) liga-se à figura do dândi, compondo o que Latuf Isaías Mucci denomina como "uma trindade, não santíssima, mas artificialíssima: o dandismo, a androginia e a artificialidade como simulacro" (1994, p. 48). Os personagens são representados como "seres repugnantes, pois repelem ao causar desgosto por suas necessidades corpóreas, pela carência na simetria das formas" (ROSENKRANZ, 1992, p. 282). Na própria etimologia da palavra "feio" nota-se que

\footnotetext{
${ }^{13}$ Tradução: "suas pupilas atraem aqueles que olham para elas".
} 
no alemão "laipsa" deriva do tocárico "t-lit-k" = ter repugnância; no grego

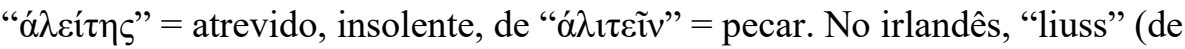
lit-tus) = horror; raiz indo-germânica "leit" = ter horror, ter insolência. No alemão atual, feio = "hässlich" vem de "hass" = ódio. "Ekel" (adjetivo e substantivo) $=$ repelente, repulsivo (alemão); "ekelig" (adjetivo) no baixoalemão; "acklig" no sueco e "ugly" em inglês, todos com a mesma significação etimológica de "repelente, repulsivo". Em polonês, feio = brzudki $($ c. bridki $)=$ agudo, repulsivo $($ TOBIAS, 1960, p. 77-78)

N'A República de Platão, o conceito de beleza é indicativo de valores, e está mais para uma noção comportamental, enquanto a "feiura, a arritmia, a desarmonia são irmãs da má linguagem e do mau-caráter" (1999, p. 94). O feio costuma ser definido como oposto ao belo, e este é definido por critérios estéticos, políticos e sociais de determinada época. Como afirma Theodor Adorno, "o belo surgiu do feio mais do que ao contrário" (1993, p. 65). A Estética do Feio, de Karl Rosenkrantz (1992), propôs o sentido de feio atrelado à moral, ao mal. O feio, portanto, associava-se ao grotesco, ao sujo, ao obsceno, ao monstruoso, ao fétido, ao desfigurado ou ao disforme, e à ideia de pecado. Para Raymond Bayer, não havia diferença entre a virtude e o conceito de belo, que representa a perfeição moral: "o que estimamos é o que é belo; logo, o bom é belo" (1995, p. 67). Segundo Janilto Andrade, “o ideário platônico da beleza deitara raízes profundas na cultura ocidental, entrando em franco declínio apenas a partir da modernidade, uma vez que os artistas desse período passam a explorar o feio como temática predominante em suas obras" $(2008, \mathrm{~s} / \mathrm{p}$.). O artista decadentista traz à tona o que Umberto Eco (2007) denomina como a "luxúria do feio": a apologia do vício, do prazer encontrado na dor e da exaltação dos estados neuróticos. Neste cenário, surge a carniça nos versos de Baudelaire, o elogio aos dentes pretos, de Tarchetti e a exaltação das catadoras de piolhos, de Rimbaud. ${ }^{14}$ Neste cenário, a Suze de António Patrício figura como uma obra de arte, perfeita, e ainda assim, "todos a achavam imensamente estranha e alguma coisa feia" ( $S$, p. 87).

Segundo Maria Rita Kehl, "um corpo é o corpo e o vazio dos corpos falantes ao seu redor. Um corpo inclui o sentido e o sem sentido da vida e a dura noção de morte, que o acompanha desde a origem até o final certeiro" (2001, s/p.). As representações femininas nas narrativas decadentistas demonstram a "sinuosa tensão com que o corpo semeador do desejo

\footnotetext{
${ }^{14}$ Referimo-nos, respectivamente, aos poemas: "Uma carniça", de Charles Baudelaire; "Os dentes pretos", de Igino Ugo Tarchetti e "Catadoras de piolhos", de Arthur Rimbaud.
} 
(de-sidare) é levado a fazer-se também como corpo semeador do desastre (dês-astre)" (COUTINHO, 2002, p. 142). Paradoxalmente, algumas personagens são descritas associandose, ao mesmo tempo, à pureza e à doença. Suze, por exemplo, possui os seios "lindos, tersos como de virgem" (S, p. 139). Carolina, por sua vez, possuía o seio "branco, assim descoberto, estreito e apetitoso como uma miniatura, mas incapaz de amamentar um filho" (AR, p. 162163). As representações de voluptuosidade são vinculadas à esterilidade das personagens. São corpos que não produzem vida, secos como a árvore do conto de Raul Brandão.

De acordo com Forestier, "more often and more simply, woman is identified with felines [...]. And lastly, woman is associated with images of death" (1983, p. 107-108). ${ }^{15}$ A proximidade da mulher com o felino, nas narrativas decadentistas, tem relação com a ideia de animalidade, de caça e mistério. Suze, por exemplo, tem "um passo ondeante de serpente fantasma" ( $S$, p. 131), "polarizando o meu desejo pro seu corpo elástico e felino" $(S$, p. 87). No conto "A Ruiva", várias são as representações femininas associadas a felinos, com traços de certa dissimulação. Na descrição de Laureana, o narrador afirma que, na tentativa de agradá-lo, "o olhar adoça-se-lhe como o dessas gatas a quem coçamos o crânio" (AR, p. 147). Já Carolina, entusiasmada com a perspectiva de tornar realidade seus anseios sexuais, "sorriu-se para mostrar os dentes, pequeninos e miúdos, de gatazinha branca" $(A R$, p. 162).

O decadentismo revela que, "na mulher, deseja-se o mistério esfíngico (Wilde), o pecado e a corrupção moral ou as carnes desfeitas (ainda Baudelaire), e mesmo a voluptuosidade da necrofilia (D'Annunzio)" (ECO, 2007, p. 354). Se, por um lado, nota-se a volúpia do protótipo de Salomé, evocada pelo famoso quadro de Gustave Moreau como a mulher fatal, sedutora e destruidora, por outro lado, existe a figura da mulher associada à esterilidade, à morte, à putrefação. $\mathrm{O}$ ventre, simbolicamente indicativo de vida, de fertilidade, associado à construção da identidade feminina, agora é o espaço habitado por vermes. Assim Suze é descrita em seu processo de decomposição: "tu que tens já talvez no ventre aberto o esverdear" ( $S$, p. 132) e Carolina, que "nasceu no dia da morte da mãe" ( $A R$, p. 150), trazia consigo "o branco apetite de sua carne anêmica, feminil e ébil” ( $A R$, p. 157).

Jocimar Daolio, afirma que "no corpo estão inscritas todas as regras, todas as normas e todos os valores de uma sociedade específica, por ser ele o meio de contato primário do indivíduo com o ambiente que o cerca" (1995, p. 105). As personagens das narrativas elencadas

\footnotetext{
${ }^{15}$ Tradução: "mais frequentemente e mais simplesmente, a mulher é identificada com os felinos [...]. E por último, a mulher é associada a imagens da morte".
} 
trazem em si uma constituição física marcada pela dicotomia da ausência e do excesso: são magras, pálidas e estéreis; mas também são lascivas, com cabelos cheios de cor e de vida e olhos penetrantes. O corpo dos personagens é o arquivo do colapso de valores e da atmosfera de descrença em que imergiu a literatura finissecular em Portugal, onde se notam descrições que remetem à sensualidade e à morte, ideias que conduzem o fio da narrativa e levam a um desfecho sombrio.

O corpo em ruínas dos personagens, que parecem irreais em sua representação bizarra, é mais que uma figuração do desagradável: é a própria decadência da noção de realidade. O corpo, mais do que um conceito biológico, figura como um local de inscrição cultural, em que os personagens materializam o vazio e a degradação do caráter, instaurando a crise da noção de beleza e de realidade, legando-nos imagens horrendas e anticonvencionais, escritas sob a pena da loucura, da neurose e do espanto. Trata-se do retrato de uma civilização doente, para a qual nada mais resta a não ser viver sob a celebração do feio, do desregramento dos sentidos, da necrofilia, do pútrido e do escatológico.

\section{REFERÊNCIAS BIBLIOGRÁFICAS}

ADORNO, Theodor. Teoria Estética. Tradução de Artur Morão. Lisboa: Edições 70, 1993.

ALMEIDA, Fialho de. “A Ruiva”. In: Contos. Lisboa: Clássica, 1914. p. 146-205.

ALMEIDA, Isabel. "Torre de Marfim”. In: CEIA, Carlos. E-Dicionário de Termos Literários. 2009. Disponível em: http://edtl.fcsh.unl.pt/encyclopedia/torre-de-marfim/. Acesso em: 17 fev. 2019.

ANDRADE, Janilto. "O feio na literatura”. In: Continente multicultural. 67. ed. Recife: CEPE, 2008.

BARCELLOS, José Carlos. "Fernando Pessoa na Evolução da Poesia Portuguesa". In: Ensaios Pessoanos: Projeto Fernando Pessoa 85. Niterói: Instituto de Letras UFF, 1985.

BAYER, Raymond. História da Estética. Tradução de José Saramago. Lisboa: Editorial Estampa, 1995.

BODEI, Remo. As formas da Beleza. Tradução de Antonio Angonese. São Paulo: EDUSC, 2005.

BOURDIEU, Pierre. A distinção: crítica social do julgamento. Tradução de Daniela Kern. São Paulo: Edusp, 2007.

BRANDÃO, Raul. A morte do palhaço e o mistério da árvore. Porto: Publicações Anagrama, 1981. . A Farsa. Lisboa: Ulmeiro, 1984. 
BUTLER, Judith. Problemas de gênero. Tradução de Renato Aguiar. Rio de Janeiro: Civilização Brasileira, 2003.

CARDIM, Leandro Neves. O corpo. São Paulo: Globo, 2009.

COURTINE, Jean-Jacques. Decifrar o corpo: Pensar com Foucault. Petrópolis: Vozes, 2013.

COUTINHO, Luiz Edmundo Bouças. "Mário de Sá-Carneiro: uma confissão decadentista". In: Annali della Facoltà di Lettere e Filosofia Università degli studi di Perugia. v. XXXVII. Perugia: 2002.

DAOLIO, Jocimar. Da cultura do corpo. Campinas, SP: Papirus, 1995.

ECO, Umberto. História da feiura. Tradução de Eliana Aguiar. Rio de Janeiro: Record, 2007. História da beleza. Tradução de Eliana Aguiar. Rio de Janeiro: Record, 2010.

ETCOFF, Nancy. A Lei do mais belo: a ciência da beleza. Tradução de Ana Luiza Borges de Barros. Rio de Janeiro: Editora Objetiva, 1999.

FEITOSA, Charles. “Alteridade na estética: reflexões sobre a feiura”. In KATZ, Chaim Samuel; KUPERMANN, Daniel; MOSÉ, Viviane. (Orgs.). Beleza, feio e psicanálise. Rio de Janeiro: Contra Capa, 2004.

FERNANDES, Maria Helena. Corpo. São Paulo: Casa do Psicólogo, 2003.

FORESTIER, Louis. "Symbolist Imagery". In: BALKANIAN, Anna. The Symbolist movement in the literature of European Languages. Budapest: Akadémiai Kiadó, 1983.

FOUCAULT, Michel. Microfísica do Poder. Rio de Janeiro: Edições Graal, 1979.

IDEIAS, José António Costa. "Decadentismo". In: CEIA, Carlos. E-Dicionário de Termos Literários. 2009. Disponível em: http://edtl.fcsh.unl.pt/encyclopedia/decadentismo/. Acesso em: 17 fev. 2019.

KAYSER, Wolfgang. Lo Grotesco - su configuración em pintura y literatura. Buenos Aires: Editorial Nova, 1964.

KEHL, Maria Rita. "Orelha do livro". In: SANT'ANNA, Denise Bernuzzi de. Corpos de passagem - ensaios sobre a subjetividade contemporânea. São Paulo: Estação Liberdade, 2001. LELOUP, Jean-Yves. O corpo e seus símbolos: uma antropologia essencial. Petrópolis, Rio de Janeiro: Vozes, 2012.

MILANEZ, Nilton. "Corpo cheiroso, corpo gostoso". In: Acta Scientiarum: Language and Culture. v. 31, n. 2, 2010, p. 215-222.

MUCCI, Latuf Isaías. Ruína e simulacro decadentista: uma leitura de Il Piacere, de D'Annunzio. Rio de Janeiro: Tempo brasileiro, 1994.

PATRICIO, Antonio. "Suze”. In: Serão Inquieto. Lisboa: Assirio e Alvim, 1979.

PEREIRA, José Carlos Seabra. “O Decadentismo” In: Decadentismo e Simbolismo na Poesia Portuguesa. Coimbra: Centro de Estudos Românicos, 1975.

PLATÃO. A República. São Paulo: Nova Cultural, 1999.

REYNAUD, Maria João. "Raul Brandão e o Expressionismo Literário: notas para uma leitura de A Farsa". In: Revista da Faculdade de Letras Língua e Literatura. XVI. Porto: 1999, p. 111123.

ROSENKRANZ, Karl. Estética de lo Feo. Traducción y edición de Miguel Salmeron. Sevilla: Julio Ollero Editor, 1992.

SÁ-CARNEIRO, Mário de. A confissão de Lúcio. 5. ed. Rio de Janeiro: Ediouro, 1995. 
SOARES, Carmem. "Corpo, conhecimento e educação: notas exparsas". In: Corpo e história. Campinas: Autores Associados, 2006.

SODRÉ, Muniz; PAIVA, Raquel. O império do Grotesco. Rio de Janeiro: Mauad, 2002. TOBIAS, José Antônio. O Feio. São Paulo: Editora Herder, 1960.

TUCHERMAN, Ieda. Breve história do corpo e de seus monstros. Lisboa: Veja, 2004.

VIÇOSO, Vítor. "Figuras da Cultura Portuguesa: Raul Brandão". In: http://www.institutocamoes.pt/cvc/figuras/rbrandao.html. Portugal: Instituto Camões, 20032006. 